\title{
OPTIMAL EVALUATION INDEX SYSTEM AND BENEFIT EVALUATION MODEL FOR AGRICULTURAL INFORMATIZATION IN BEIJING
}

\author{
Chen Ma, ${ }^{*, * *}$ Jin Li, ${ }^{*}$ and Dongyang Wang,*,***
}

\begin{abstract}
The level of informatization is an important indicator of a country or region's level of economic development, and many domestic and foreign scholars have studied this topic. Informatization is seen as a developing social phenomenon, with both national and regional characteristics, therefore the foreign standard systems are not entirely suitable for the development of an information society in China. This paper establishes new indexes and designs an optimal evaluation index system according to the characteristics of informatization. The optimal index system is more suitable for the current development of informatization in China. Using this index system, we measure the informatization level in Beijing from 2003 to 2012. Using the Cobb-Douglass model, we construct an information benefit evaluation model to verify the positive effect of informatization on economic development in Beijing. To further study the relationship between the informatization evaluation index and the urban-rural income gap, we conduct a regression between the information evaluation index and the urban-rural income gap. It provides a quantitative scientific basis for the study of the impact of information technology on economic and social development plans, enabling improved government decision-making.
\end{abstract}

\section{Key Words}

Agricultural informatization, evaluation index system, benefit evaluation model, urban-rural income gap, Beijing city

\section{Introduction}

Since the late 20th century, the information revolution has entered a period of accelerated development. The rise of information technology has had a profound impact on the development of the national economy, enabling

* Beijing Research Center for Information Technology in Agriculture, Beijing, 100097, China; e-mail: \{mac, lij\}@nercita.org.cn

** Institute of Agricultural Economics and Development, Chinese Academy of Agricultural Sciences, Beijing, 100081, China; e-mail: wangdongyang@caas.cn

*** Institute of Food and Nutrition Development, Ministry of Agriculture, Beijing, 100081, China

Recommended by Prof. Simon X. Yang

(DOI: 10.2316/Journal.206.2018.1.206-5433) the transformation and upgrading of traditional industries. Presented with the strategic opportunities offered by developments in information technology, the governments of various countries have developed strategies to guide the transformation and development of a range of industries. The Chinese government has attached great importance to the use of information technology to promote economic restructuring and development, and has put forward strategic guidelines focusing on driving industrialization with informatization [1].

Being a driving force of economic development, the level of informatization is an important indicator of a country or region's economic development, and many domestic and foreign scholars have studied this topic. Machlup analysed the knowledge industry and its distribution in the United States in 1962 [2]. Porat improved Machlup's knowledge industry concept, proposing a method involving four industrial divisions, and created a system of economic accounting to calculate the levels of informatization, production, and labour in the United States in 1967 [3]. Japan Research Institute of Telecom and Economic (RITE) calculated the degree of informatization in 46 Japanese counties using the RITE model, which measures the amount of information, the information equipment rate, the level of communication, and the information coefficient [4]. Among domestic scholars, Zou et al. were the first to evaluate the level of informatization, using the RITE model to measure the level of information in China in 1986 [5]. Later, Liu [6], Chen [7], and others evaluated the level of informatization using six key elements of agricultural informatization and three indices of an informatization index system. Informatization is a developing social phenomenon with both national and regional characteristics; therefore, the RITE model used by foreign scholars is not entirely suitable for the development of an information society in China. The measurements obtained by domestic scholars mostly reflect the entire country's information level, but do not reflect the levels in specific regions [8]-[10].

On the basis of previous studies, this article establishes an optimal index system, and then introduces some new indicators according to the characteristics of informatization 
to form a new index system. This index system is more suitable for the current development of informatization in China, and has a strong operational bias. Beijing is the capital of China with a high level of information infrastructure construction. After nearly a decade of development, its level of informationization has reached the level of developed countries in the world. Therefore, Beijing provides a good example, and the index system can provide a reference for the future of other Chinese provinces and cities. Finally, using the Cobb-Douglass model, we construct an informatization benefit evaluation model to verify the positive effect of informatization on economic development in Beijing. This index system is not only able to effectively reflect the development of information technology in Beijing but is also able to empirically test the relationship between information technology and economic development, providing a quantitative scientific basis for the study of the impact of information technology on economic and social development plans, enabling improved government decision-making.

\section{Materials and Methods}

\subsection{Data Sources}

This study uses data from the China Statistical Yearbook, the China Information Almanac, China's Population and Employment Statistics Yearbook, the Chinese Industry
Yearbook, the China Radio and TV Yearbook, the Beijing Statistical Yearbook, the China Internet Development Statistics Report, and other sources for the 10-year period from 2003 to 2012 to evaluate the development of informatization in Beijing. The period from 2003 to 2012 is selected because some data for 2013 and 2014 are not available as a result of a lag in the statistical yearbook data.

Because of data limitations, "information industry" in "the proportion of the number of practitioners in the information industry" and "information industry output per capita" is replaced by "tertiary industry", and "the proportion of industrial value added" is replaced by "the added value of the information industry".

\subsection{Design of the Evaluation Index System}

There are two main theoretical models used to measure the level of informatization. One is the Porat method, which is studied from an economic perspective by Machlup and Porat. The other is the Japanese RITE model, which reflects the extent of the development of an information society in terms of information flow and information-related ability [11]-[13].

The Porat method uses three main measurement indicators: the proportion of information activity output value to GNP or GDP, information sector employment as a proportion of total employment, and the proportion of information sector employed income accounted for total employment (Table 1). This method relies heavily on

Table 1

The Porat Method

\begin{tabular}{|c|c|c|}
\hline \multicolumn{2}{|c|}{ Information Department } & \multirow{2}{*}{$\begin{array}{l}\text { Information Industry } \\
\text { Research and development industry; } \\
\text { inventive industry; civil service industries }\end{array}$} \\
\hline 1. & $\begin{array}{l}\text { Knowledge production } \\
\text { and invention industry }\end{array}$ & \\
\hline 2. & $\begin{array}{l}\text { Information distribution } \\
\text { and communications } \\
\text { industry }\end{array}$ & $\begin{array}{l}\text { Education; information service bulletin; } \\
\text { the official communication media; } \\
\text { informal communication media }\end{array}$ \\
\hline 3. & Risk management & $\begin{array}{l}\text { Various types of risk industry; } \\
\text { all kinds of financial services; } \\
\text { speculative economy industry }\end{array}$ \\
\hline 4. & $\begin{array}{l}\text { Industry research and } \\
\text { regulation industry }\end{array}$ & $\begin{array}{l}\text { Investigation and non-speculative } \\
\text { brokerage industry; the advertising industry; } \\
\text { non-market research firms }\end{array}$ \\
\hline 5. & $\begin{array}{l}\text { Information processing } \\
\text { and delivery services } \\
\text { industry }\end{array}$ & $\begin{array}{l}\text { Non-electronic processing industry; } \\
\text { electronic processing industry; } \\
\text { telecommunications infrastructure; }\end{array}$ \\
\hline 6. & $\begin{array}{l}\text { Information products } \\
\text { industry }\end{array}$ & $\begin{array}{l}\text { Non-electric consumption or intermediate products; } \\
\text { non-speculative electronic products; } \\
\text { electronic consumption or intermediate products; } \\
\text { electronic investment products }\end{array}$ \\
\hline 7. & $\begin{array}{l}\text { Some government } \\
\text { activities }\end{array}$ & $\begin{array}{l}\text { The first information sector in the federal } \\
\text { government; postal services; state and local education }\end{array}$ \\
\hline 8. & Infrastructure & Information building and rent \\
\hline
\end{tabular}




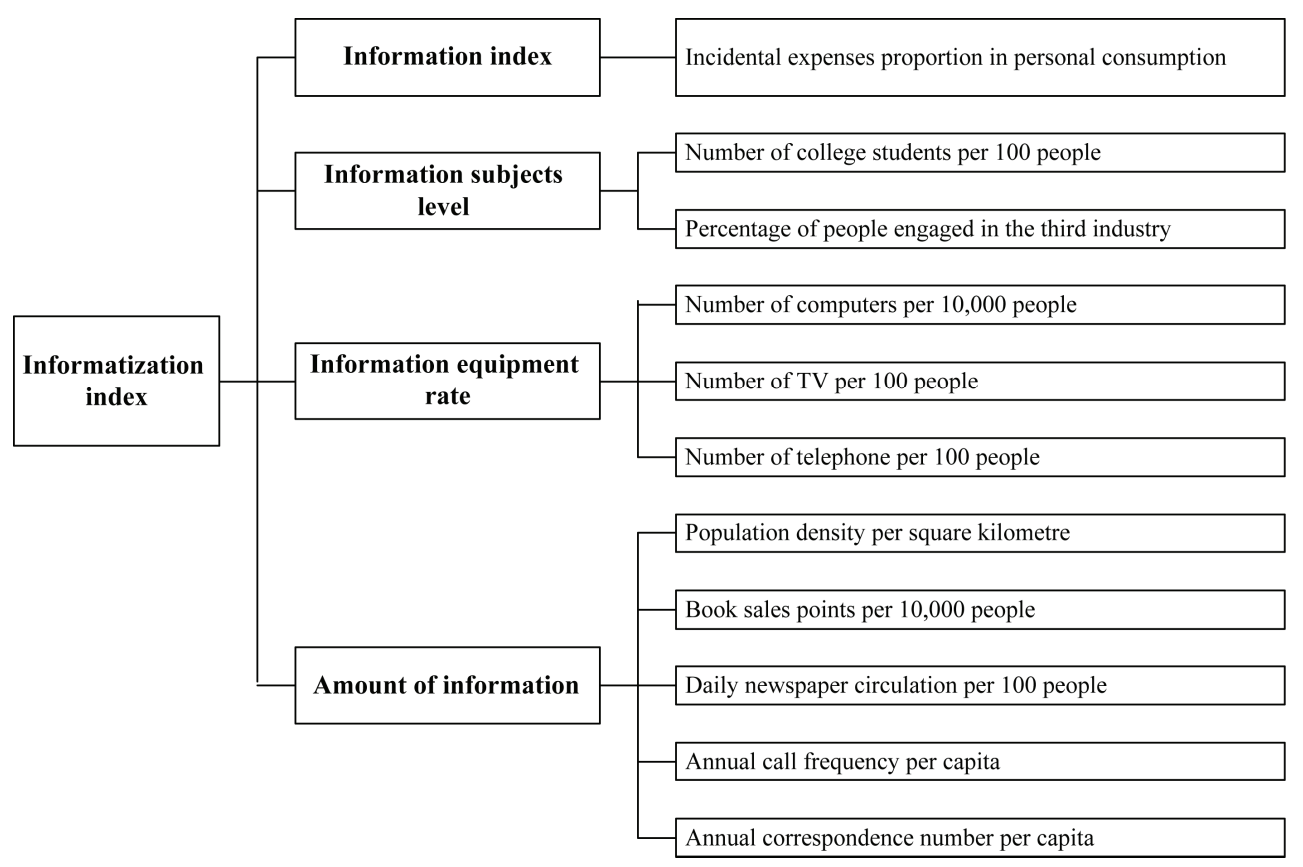

Figure 1. Index system of the RITE model.

statistical data, and because the current statistical system in use in China is quite different to that used in the United States, this method is not suitable for China [14]-[16].

The RITE model mainly measures four primary elements, which are divided into 11 secondary elements. However, because the statistical method used in China is different to that used in Japan, the RITE model (Fig. 1) is not practical for use in China [17]-[19].

Based on the existing literature and the 13th FiveYear Plan, combined with national conditions and levels of economic development in China, this study identifies 5 potential variables and 13 observation variables. The index system can provide a comprehensive evaluation of the development of information technology in Beijing and a scientific basis for the development of informatization in Beijing [20]-[22] (Fig. 2).

(1) Infrastructure Index

Infrastructure provides the basic underlying conditions enabling the development of information technology, and is composed of four indicators. Fixed telephone ownership and mobile phone ownership reflect the popularity of the telephone application level; the computer ownership rate reflects the application level of computers; and the TV ownership rate reflects the application level of the network television business.

(2) Industrial Technology Index

Industrial technology directly reflects the process of informatization, and also determines whether or not the public can enjoy high-quality information technology services. The industrial technology index is composed of two indicators: the telecommunications industry output per capita and invention patent applications per million people reflect the contribution of the telecommunications industry output levels and technological innovations in information technology.

(3) Consumer Applications Index
The consumer applications index reflects the level of application of information technology in people's daily work life, and is composed of two indicators: Internet penetration and consumption of information per capita monitor the level of application of information from the perspective of society and the public.

(4) Knowledge Support Index

Knowledge is a necessary condition if people are to use information and communication technology effectively; the higher the level of knowledge, the higher the level of application of information communication technology. The education index is calculated using the formula published by the United Nations Development Programme (Education Index $=$ Adult Literacy Rate $\times 2 / 3+$ average schooling year $\times 1 / 3$ ). This reflects the external knowledge support structure provided by informatization. The proportion of the number of practitioners of informatization reflects the internal knowledge support structure provided by informatization.

(5) Development Effect Index

This is mainly used to measure the development of information technology in the fields of $R \& D$, innovation, and energy efficiency, and is composed of three indicators: proportion of industrial value added, proportion of information industrial R\&D funding, and GDP per capita.

\subsection{Method of Calculating the Evaluation Index}

First, we use a standard method to standardize the original data as follows:

Transform the sequence $x_{1}, x_{2}, \ldots, x_{n}$ such that

$$
y_{i}=\frac{x_{i}-\min _{1 \leq j \leq n}\left\{x_{j}\right\}}{\max _{1 \leq j \leq n}\left\{x_{j}\right\}-\min _{1 \leq j \leq n}\left\{x_{j}\right\}}
$$




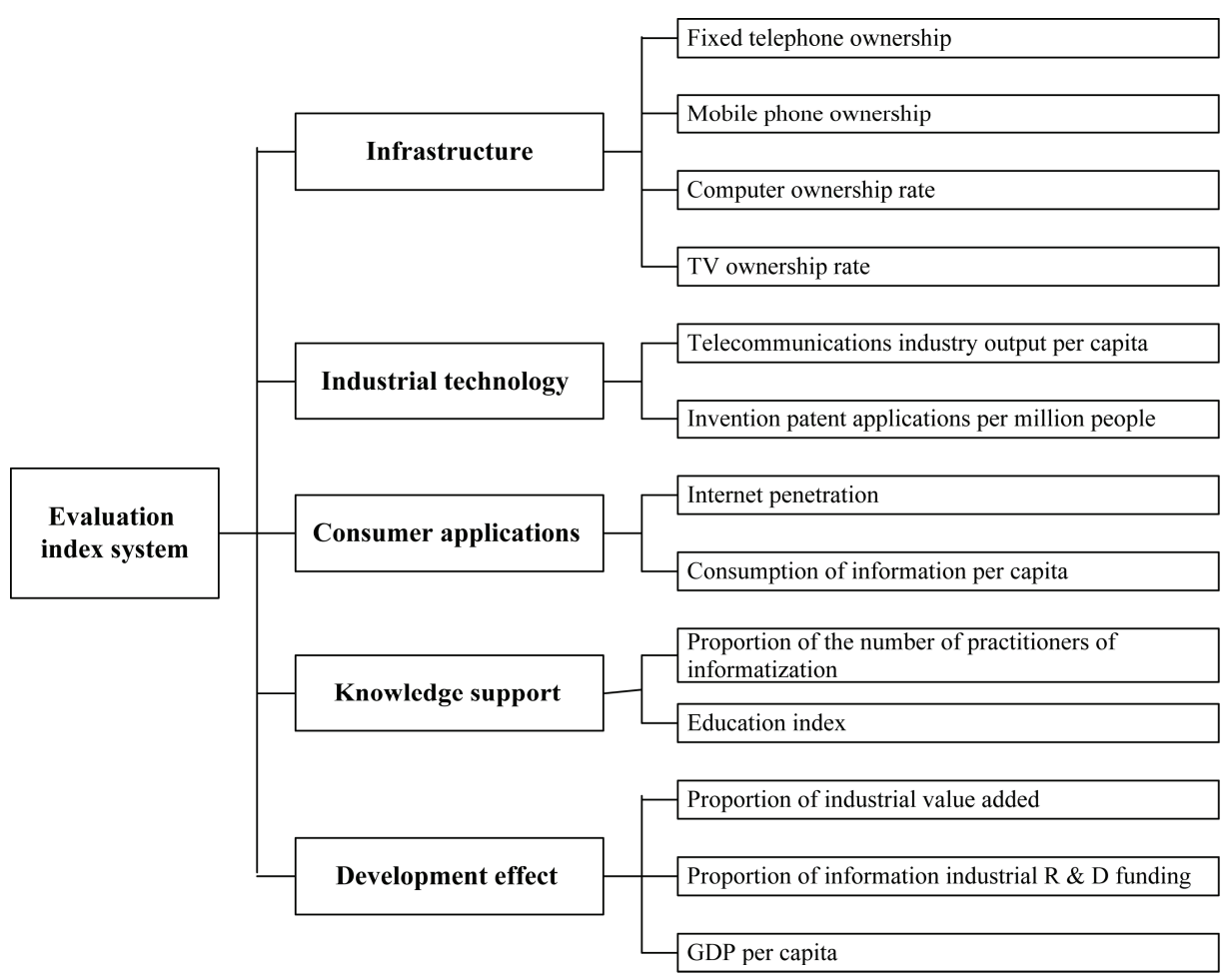

Figure 2. The optimal agricultural informatization evaluation index system.

Table 2

Weights of the Evaluation Index System

\begin{tabular}{|c|c|c|c|}
\hline Latent Variables & Weights & Observed Variables & Weights \\
\hline \multirow[t]{4}{*}{ Infrastructure } & $22 \%$ & Fixed telephone ownership & $5.50 \%$ \\
\hline & & Mobile phone ownership & $5.50 \%$ \\
\hline & & Computer ownership rate & $5.50 \%$ \\
\hline & & TV ownership rate & $5.50 \%$ \\
\hline \multirow[t]{2}{*}{ Industrial Technology } & $17 \%$ & $\begin{array}{l}\text { Telecommunications industry output } \\
\text { per capita }\end{array}$ & $8.50 \%$ \\
\hline & & $\begin{array}{l}\text { Invention patent applications per } \\
\text { million people }\end{array}$ & $8.50 \%$ \\
\hline \multirow[t]{2}{*}{ Consumer Applications } & $21 \%$ & Internet penetration & $10.50 \%$ \\
\hline & & Per capita consumption of information & $10.50 \%$ \\
\hline \multirow[t]{2}{*}{ Knowledge Support } & $19 \%$ & $\begin{array}{l}\text { The proportion of the number of } \\
\text { practitioners of informatization }\end{array}$ & $9.50 \%$ \\
\hline & & Education index & $9.50 \%$ \\
\hline \multirow[t]{3}{*}{ Development Effect } & $21 \%$ & The proportion of industrial value added & $7.00 \%$ \\
\hline & & $\begin{array}{l}\text { Proportion of information industrial R\&D } \\
\text { funding }\end{array}$ & $7.00 \%$ \\
\hline & & GDP per capita & $7.00 \%$ \\
\hline
\end{tabular}

The new sequence is dimensionless, i.e., $y_{1}, y_{2}, \ldots$, $y_{n} \in[0,1]$.

Second, we adopt the qualitative Delphi method to determine each evaluation index weights in determining the level of development of informatization in Beijing, and then calculate the corresponding relationship between the total index and various factors. The weights are shown in Table 2. 
Table 3

Comprehensive Evaluation of the Level of Informatization in Beijing

\begin{tabular}{|c|c|c|c|c|c|c|}
\hline Year & $\begin{array}{c}\text { Infrastructure } \\
\text { Construction }\end{array}$ & $\begin{array}{c}\text { Industrial } \\
\text { Technology }\end{array}$ & $\begin{array}{c}\text { Application } \\
\text { Consumption }\end{array}$ & $\begin{array}{c}\text { Knowledge } \\
\text { Support }\end{array}$ & $\begin{array}{c}\text { Development } \\
\text { Effect }\end{array}$ & $\begin{array}{c}\text { Total } \\
\text { Score }\end{array}$ \\
\hline 2003 & 0.1314 & 0.0328 & 0.0396 & 0.0298 & 0.0833 & 0.3169 \\
\hline 2004 & 0.1583 & 0.0402 & 0.0405 & 0.0569 & 0.1129 & 0.4088 \\
\hline 2005 & 0.1802 & 0.0517 & 0.0532 & 0.0619 & 0.1252 & 0.4722 \\
\hline 2006 & 0.1900 & 0.0635 & 0.0695 & 0.0719 & 0.1417 & 0.5365 \\
\hline 2007 & 0.1282 & 0.0789 & 0.0902 & 0.0743 & 0.1648 & 0.5364 \\
\hline 2008 & 0.0931 & 0.0976 & 0.1074 & 0.0865 & 0.1479 & 0.5325 \\
\hline 2009 & 0.1148 & 0.1060 & 0.1345 & 0.0928 & 0.1285 & 0.5766 \\
\hline 2010 & 0.1278 & 0.1181 & 0.1645 & 0.0965 & 0.1349 & 0.6418 \\
\hline 2011 & 0.1454 & 0.1496 & 0.1886 & 0.0940 & 0.1370 & 0.7146 \\
\hline 2012 & 0.1686 & 0.1700 & 0.2100 & 0.1011 & 0.1400 & 0.7897 \\
\hline
\end{tabular}

Assuming a factor set of $U=\left\{u_{1}, u_{2}, \ldots, u_{n}\right\}$, the weight of each factor is given by $k$ independent experts as follows:

$$
\begin{aligned}
a_{i} & =\frac{1}{k} \sum_{j=1}^{k} a_{i j}, \text { where } i=1,2, \ldots, n, \text { that is, } \\
A & =\left(\frac{1}{k} \sum_{j=1}^{k} a_{1 j}, \frac{1}{k} \sum_{j=1}^{k} a_{2 j}, \ldots, \frac{1}{k} \sum_{j=1}^{k} a_{n j}\right)
\end{aligned}
$$

An index system composed of infrastructure, industrial technology, consumer applications, knowledge support, and development effectiveness provides the first-level index, and each first-level indicator also consists of a number of second-level indicators. Therefore, this study uses the linear programming method to solve the problem of combining multiple indices into a single index, and calculates the level of informatization development evaluation index in Beijing. The first-level indicators are calculated using the following formulae.

Infrastructure index:

$$
F_{1}=\sum_{j=1}^{4} f_{i j} .
$$

that is,

$$
F_{1}=\sum_{j=1}^{4} w_{j} f_{i j}
$$

Industrial technology index:

$$
F_{2}=\sum_{j=5}^{6} w_{j} f_{i j}
$$

Application of the consumer price index:

$$
F_{3}=\sum_{j=7}^{8} w_{j} f_{i j}
$$

Knowledge support index:

$$
F_{4}=\sum_{j=9}^{10} w_{j} f_{i j}
$$

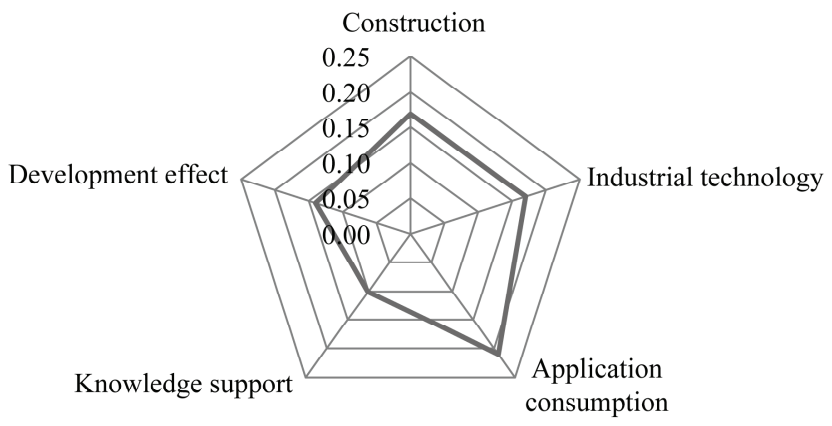

Figure 3. Development of informatization in Beijing in 2012.

Development of effective index:

$$
F_{5}=\sum_{j=11}^{13} w_{j} f_{i j}
$$

Sum of available information index:

$$
F=\sum_{j=1}^{n} F_{j}
$$

\section{Results and Discussion}

\subsection{Evaluation of the Level of Agricultural Informa- tization in Beijing}

The various types of standardized data relating to the level of informatization in Beijing are substituted into the above model. The results are shown in Table 3.

The informatization level in Beijing has been rising steadily since 2003. Although the development of information technology was stagnant during the period of economic crisis in 2008, the informatization index had risen 0.4728 points in 2012 compared with the level in 2003 (Fig. 3). Of the latent variables, the consumer applications index is the highest, measuring 0.21 points. 


\subsection{The Agricultural Informatization Benefit Evaluation Model}

To further study the practical significance of the informatization evaluation index, we constructed an information benefit evaluation model, based on the Cobb-Douglass model, to verify the positive effect of informatization on economic development in Beijing. The model is calculated as follows:

$$
Y_{t}=A \cdot K_{t}^{\alpha} L_{t}^{\beta},
$$

where $Y$ represents the total output of society or the gross domestic product, $A$ represents the technological progress factor, $K$ represents the input of capital, $L$ represents the input of labour, $\alpha$ represents the output elasticity of capital, and $\beta$ represents the output elasticity of labour.

The study divides technology into two parts: information technology and non-information technology. Then, the formula can be expressed as:

$$
A=A_{0} \cdot I_{t}^{\gamma},
$$

where $I$ represents the level of information, $\gamma$ represents the output elasticity of the information level, and $A_{0}$ represents technical progress factors other than information technology. Thus, the Cobb-Douglass production function is rewritten as:

$$
Y_{t}=A_{0} \cdot K_{t}^{\alpha} \cdot L_{t}^{\beta} \cdot I_{t}^{\gamma}
$$

Due to the general assumption: scale economies unchanged, it can be regularized process as:

$$
\alpha+\beta+\gamma=1 \text {. }
$$

Then, the Cobb-Douglass production function is rewritten as:

$$
Y=A_{0} \cdot K_{t}^{\alpha} \cdot L_{t}^{1-\alpha-\gamma} \cdot I_{t}^{\gamma}
$$

The formula is then presented with both sides divided by $L_{t}$ :

$$
\frac{Y_{t}}{L_{t}}=A_{0}\left(\frac{K_{t}}{L_{t}}\right)^{\alpha}\left(\frac{I_{t}}{L_{t}}\right)^{\gamma}
$$

By taking the logarithm of the model, a linear equation is obtained as follows:

$$
\ln P G D P=C+\alpha \ln P K+\gamma \ln P I,
$$

where $C=\ln A_{0}$ is a constant term; $P G D P=\frac{Y_{t}}{L_{t}}$ is labour productivity; $P K=\frac{K_{t}}{L_{t}}$ is the capital equipment rate; and $P I=\frac{I_{t}}{L_{t}}$ is the IT equipment rate.

To better see the relationship between them, the study takes the logarithm, and the scattered point diagrams shown in Figs. 4 and 5.

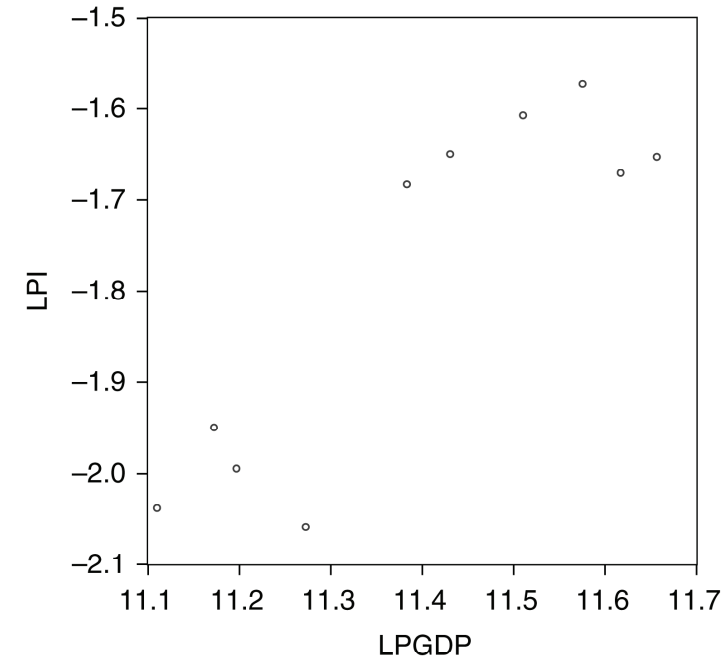

Figure 4. Scatter-point diagram of PGDP and PI.

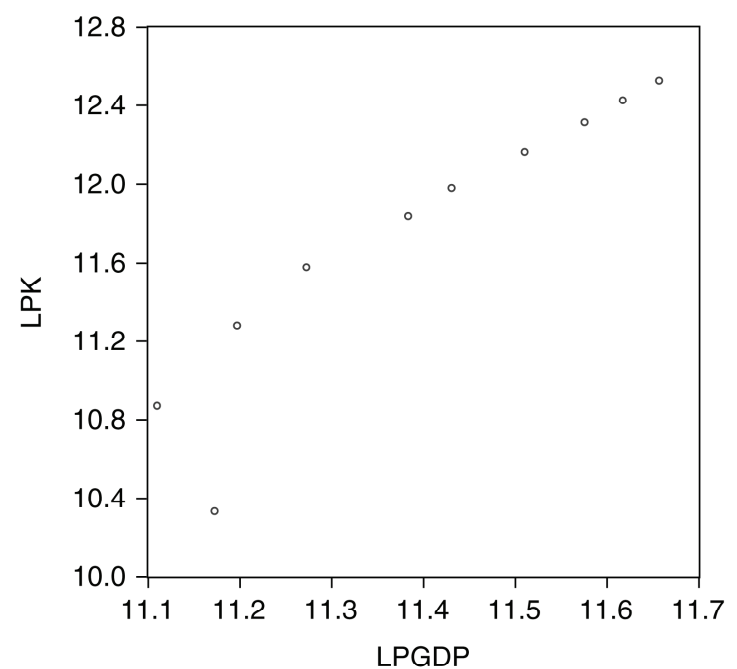

Figure 5. Scatter-point diagram of PGDP and PK.

It can be seen that GDP per capita in Beijing has a strong linear correlation with the information index and fixed assets investment per capita from 2003 to 2012.

$$
\begin{aligned}
& L \widehat{P G D} P_{t}=9.9968+0.3708 L P I_{t}+0.1756 L P K_{t} \\
& (0.8509) \quad(0.1787) \\
& t=(11.7505) \quad(2.0742) \\
& R^{2}=0.9208
\end{aligned}
$$

The model can be transformed into the following form:

$$
Y_{t}=9.997 K_{t}^{0.18} L_{t}^{0.45} I_{t}^{0.37}
$$

The Durbin-Watson test value of the regression equation is about 1.0224. This indicates that the error terms are not auto correlated in the model. Based on the results of the least squares method, the goodness of fit of the equation is 0.9208 . This means that the informatization 
index and per capita investment in fixed assets explains the vast majority of the differences in per capita GDP. The sample data show goodness of fit with the information benefit evaluation model. The output elasticity of informatization in Beijing is 0.37. This indicates that when the level of informatization in Beijing increases by $1 \%$, the size of the regional economy will increase by $0.37 \%$. This shows that informatization has become a significant factor in the development of the economy in Beijing, and further improvement in the level of informatization will promote economic growth.

\subsection{Impact of Informatization on the Urban-Rural Income Gap in Beijing}

To further study the informatization evaluation index in relation to the urban-rural income gap, we conduct a regression between the information evaluation index and the urban-rural income gap, and the regression process is as follows.

To prevent spurious regression, it is necessary to carry out a unit root test on the data. We use the Eviews statistical software (developed by Quantitative Micro Software) to test the income gap between urban and rural areas in Beijing $(U R I G)$ and the informatization index $(I)$. The results show that the data are not stable, and there is a unit root. Therefore, the data are processed by first-difference transformation, and then the unit root test is carried out again. The test results are shown in Table 4.

Table 4

Unit Root Test Results

\begin{tabular}{|l|c|c|}
\hline & Statistic & Prob.** \\
\hline URIG & -1.981499 & 0.2871 \\
\hline DURIG & -6.722748 & 0.0010 \\
\hline I & -0.986881 & 0.7077 \\
\hline DI & -2.964217 & 0.0802 \\
\hline
\end{tabular}

Regression analysis is performed using the Eviews software, and the results are shown below.

$$
\begin{aligned}
U R I G_{t}= & 2.73-0.72 I_{t}+\varepsilon_{t} \\
& (56.45) \quad(-8.25) \\
R^{2}= & 0.89, \quad D W=2.16,
\end{aligned}
$$

where $t=$ the year (2003-2012).

The goodness of fit of the model is 0.89 , and the DW test value of the regression equation is 2.16 , so there is a linear correlation between the urban-rural income gap and the informatization index. The regression coefficient of the model is -0.72 . This shows that when the informatization level in Beijing increases by $1 \%$, the urban-rural income gap is reduced by $0.72 \%$.

Therefore, the informatization index reflects the relationship between the level of informatization development and the urban-rural income gap. Thus, this study enriches the existing literature and provides the foundation for setting priorities.

\section{Conclusion}

Based on previous research by foreign scholars, we establish a new evaluation index for informatization in Beijing using the characteristics of the development of information technology in China, and the level of informatization in Beijing is evaluated during the period 2003-2012. The data requirements of the new evaluation index system are relatively loose, more in line with China's statistical system, and more operational.

To verify the accuracy and effectiveness of the evaluation index, we improve the Cobb-Douglas production function model and treat information technology as a separate element to evaluate the influence of informatization on economic growth and on the urban-rural income gap. The results show that when the level of informatization in Beijing increases by $1 \%$, the regional economy increases by $0.37 \%$, there is a negative correlation between the urbanrural income gap and the informatization index, and the coefficient of elasticity is -0.72 . Therefore, the evaluation index presented in this paper provides an accurate reflection of the level of informatization. We believe that our work will provide significant benefits in promoting agricultural informatization.

This study enriches the existing information technology index system, and defines the relationship between the informatization index and economic development, and that between the informatization index and the urban-rural income gap.

\section{Acknowledgement}

This research was financially supported by the Beijing Social Science Fund (14JGB053), Beijing Academy of Agriculture and Forestry Sciences Innovation Ability Construction Project (KJCX20160501), Beijing Natural Science Foundation(9162006), and Beijing Municipal Science and Technology Commission Science and Technology Innovation Center Construction Strategy Research and Expert Consultation Project (Z161100003116001).

\section{References}

[1] Reports in the 16th National CPC Congress, http://baike. baidu.com/link?url=zoLJs51pnE2GUF2rVyU4CHJsqO7ljfB4 XWIpYmSPY-JiKuaoqHjBZiPylP0TopS_cWXNcNLT-wOgH 0v7jN zoqEz3mtvQEWnsEHJhh0e1Ny

[2] F. Machlup, The Production and distribution of knowledge in the United States (Princeton, NJ: Princeton University Press, 1962).

[3] F. Machlup, Information economics (Beijing: China Outlook Press, 1987).

[4] W. Xihe, Comparison and analysis of four methods of measuring social information, Researches in Library Science, 2008, 10(03), $12-14$.

[5] China Science and Technology Development Research Center, Informatization - the mission of history (Beijing: Publishing House of Electronics Industry, 1987). 
[6] L. Shihong, Research on the theory and method of information evaluation in rural areas of China (Beijing: Chinese Academy of Agricultural Sciences, 2008).

[7] C. Chunhui, Regional informatization index system and evaluation methods, Statistics and Decision, 32(2), 2003, 10-13.

[8] A.P. Nugroho, T. Okayasu, E. Inoue, Y. Hirai, and M. Mitsuoka, Development of actuation framework for agricultural informatization supporting system, IFAC Proceedings Volumes, 46(4), 2013, 181-186.

[9] C. Liu, The myth of informatization in rural areas: The case of China's Sichuan province, Government Information Quarterly, 29(1), 2012, 85-97.

[10] C. Ting and F. Yi, ICT policy for the "socialist new countryside" - A case study of rural informatization in Guangdong, China, Telecommunications Policy, 37(8), 2013, 626-638.

[11] Y. Xu, F-Q. Niu, L. Bergmann, Z.Q. Wang, J. Wang, A dairy industry information cooperative service system based on a production process ontology, Journal of Integrative Agriculture, 11(5), 2012, 839-848.

[12] J. Wenshen, P. Ligang, Q. Yuange, W. Jihua, and W. Wenfu, Agro-food farmland environmental monitoring techniques and equipment, Procedia Environmental Sciences, 24(10), 2011, $2247-2255$.

[13] Y. Liu, L. Jiao, Y. Liu, and J. He, A self-adapting fuzzy inference system for the evaluation of agricultural land, Environmental Modelling \& Software, 40, 2013, 226-234.

[14] A. Allam, A. Fleifle, A. Tawfik, C. Yoshimura, and A. El-Saadi, A simulation-based suitability index of the quality and quantity of agricultural drainage water for reuse in irrigation, Science of The Total Environment, 536, 2015, 79-90.

[15] S.W. Xu, G.Q. Li, and Z.M. Li, China agricultural outlook for 2015-2024 based on China Agricultural Monitoring and Earlywarning System (CAMES), Journal of Integrative Agriculture, 14, 2015, 1889-1920.

[16] F. Rahmanipour, R. Marzaioli, H.A. Bahrami, Z. Fereidouni, and S.R. Bandarabadi, Assessment of soil quality indices in agricultural lands of Qazvin Province, Iran, Ecological Indicators, 40, 2014, 19-26.

[17] Z. Ahmad and M. Jun, Agricultural production structure adjustment scheme evaluation and selection based on DEA Model for Punjab (Pakistan), Journal of Northeast Agricultural University (English Edition), 22(2), 2015, 87-91.

[18] X. Wang, J. Shen, and W. Zhang, Energy evaluation of agricultural sustainability of Northwest China before and after the grain-for-green policy, Energy Policy, 67, 2014, 508-516.

[19] J. Xia and T-J. Lu, Bridging the digital divide for rural communities: The case of China, Telecommunications Policy, 32(9), 2008, 686-696.

[20] G.U. Chaolin, W.U. Liya, and I. Cook, Progress in research on Chinese urbanization, Frontiers of Architectural Research, 1(2), 2012, 101-149.

[21] C-W. Su, T-Y. Liu, H-L. Chang, and X-Z. Jiang, Is urbanization narrowing the urban-rural income gap? A cross-regional study of China, Habitat International, 48, 2015, 79-86.

[22] Y. Li, X. Wang, Q. Zhu, and H. Zhao, Assessing the spatial and temporal differences in the impacts of factor allocation and urbanization on urban-rural income disparity in China, 2004-2010, Habitat International, 42, 2014, 76-82.

\section{Biographies}

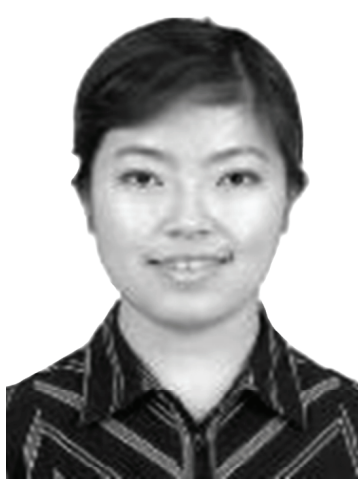

Chen $M a$ was born in 1985. She received her master's degree in industrial economics in 2012, and then she worked in Beijing Research Center for Information Technology in Agriculture. She is now studying Ph.D. in agricultural economic management at the Chinese Academy of Agricultural Sciences. Her current research includes agricultural informatization and agricultural economic management.

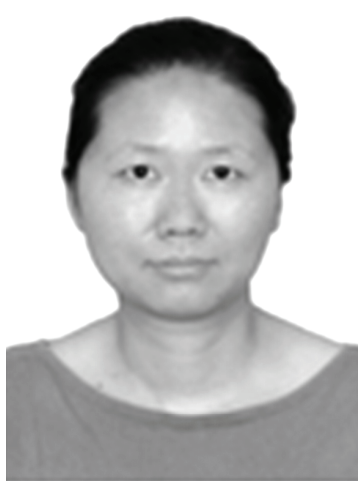

Jin $L i$ was born in 1978. She received her Ph.D. in agricultural economic management. She is now an associate professor in Beijing Research Center for Information Technology in Agriculture, Beijing, China. Her current researches include agricultural informatization and agricultural economic management.

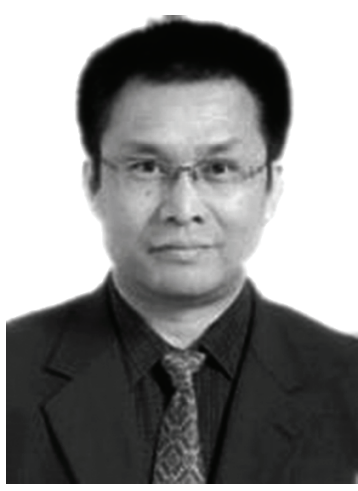

Dongyang Wang was born in 1964. He received his Ph.D. in agriculture in 1992. He is now the Ph.D. Tutor of the Institute of Agricultural Economics and Development, CAAS. And he is now the Professor of Institute of Food and Nutrition Development, Ministry of Agriculture. His current research includes agricultural informatization and agricultural economic management. 